\title{
Business advice and lending in small firms
}

\begin{abstract}
The literature on lending to small firms has primarily focused on the mechanisms and methods used to evaluate entrepreneurs and businesses and on the types of firms that are more likely to experience unfavourable application outcomes. That is, the focus of most empirical research is on supply-side decisions. The current research attempts to shed some light on demand-side considerations. Drawing upon data collected as the UK SME Finance Monitor (2011-2014), we identify links between entrepreneurs' diligence, business risk and finance-related advice-seeking prior to initiating loan and overdraft applications. The results show evidence of the usefulness of advice in ameliorating, both structural and strategic, business risk and improving the prospects of successful debt applications to banks.
\end{abstract}

\section{Keywords}

Small and Medium sized firms, Business advice, Business risk, effect of advice 


\section{Introduction}

Support for the creation and development of small firms is a central component of the industrial policies of most nations (Blackburn 2016)(Blackburn 2016). A central concern for policy in all countries has been with the difficulty SMEs may face in accessing bank loans (Beck et al. 2013; Canton et al. 2013). Due to relative information opacity, small firms represent riskier prospects to potential sources of finance (Berger \& Udell 2003; Kirschenmann 2016; Stiglitz \& Weiss 1981). For banks, as the primary source of external finance, asymmetric information manifests in a greater risk of moral hazard and higher agency costs of debt. The firm owner, who is typically also the manager and key decision maker, has an incentive to pursue riskier projects since the costs of these risks are disproportionately borne by the lender (Berger \& Udell 2003; Stiglitz \& Weiss 1981). Lending to small firms (and lending smaller amounts) carries disproportionately higher costs of due diligence (Treichel \& Scott 2006); with these costs inflated in the face of limited credit histories or audited financial statements. Largely for these reasons, smaller firms have historically been identified as especially susceptible to credit rationing.

However, through the use of different lending mechanisms, evidence suggests that banks and small firms manage to avoid credit rationing on a general basis (Berger \& Black 2011; Kremp \& Sevestre 2013; Parker 2002). The provision of collateral, the imposition of shorter maturity terms, the insertion of covenants, and the setting of 
varying prices gives the tool to banks and entrepreneurs to reach terms of contract that are acceptable to both sides(Berger \& Udell 2003; Peltoniemi \& Vieru 2013). Nonetheless, while recognising that most small firm applicants are ultimately able to obtain debt financing (Vos et al. 2007; Cowling et al. 2012), there is some evidence of loan scaling ${ }^{1}$ or structural higher pricing faced by specific segments such as innovative and growing firms (Nitani \& Riding 2013; Rostamkalaei \& Freel 2016; Lee et al. 2014). One potential source of market failure results from consumers being poorly informed about the quality and prices of alternatives in the market before making decisions (Storey 2003). On the supply side, different lending technologies have been investigated and the potential effect of these methods on small firms have been discussed (Berger et al. 2005; Berger \& Udell 2006; Berger \& Black 2011). However, we are much less informed about the readiness of the entrepreneur to approach external financiers. An important part of successful lending processes depends on entrepreneurs' decisions about when, where, and how to apply for external financing.

An example of the effect of imperfect information on the demand-side is the case of “discouraged borrowers" (Kon \& Storey 2003; Freel et al. 2010; Xiang et al. 2015). Discouraged borrowers do not apply for credit because they fear rejection - despite their declared neediness and despite being observationally indistinguishable from those who applied for and received money. There is also evidence that some entrepreneurs face

\footnotetext{
${ }^{1}$ In the current context, loan scaling is the practice of being offered some proportion of the funds requested, but less than the full amount.
} 
initial rejection or are presented with unsuitable terms of contract at the first attempt and must re-apply, renegotiate, or switch banks for a better deal. For example, in the current data set, $40 \%$ and $25 \%$ of firms seeking loan and overdraft funding, respectively, report initial rejection or did not accept the initial terms of contract. Not being well informed about available alternatives and prices may lead entrepreneurs to avoid requesting external funds or increase the risks of initial rejection. In contrast, some applicants are likely to be more aware of potential information and resource gaps and, accordingly, will be better placed to make an 'educated' decision. In short, our concern is with how well the demand-side is informed about external financing before initiating the applications process.

Our research draws upon this idea and investigates the role of business advisors in preparing small businesses to request external finance. We speculate that higher financial awareness on the part of the entrepreneur and a higher degree of business risk will both associate with a higher probability of understanding the knowledge gap and, accordingly, of seeking advice. Our paper seeks to study this group of bank clients and the effect of advisory services in ameliorating resource access pressures. If business advice reduces information and risk asymmetries, by allowing firms to better present themselves to banks, then firms may experience better initial outcomes than similar non-advice seeking firms. 
Drawing on data from the UK SME Finance Monitor, our paper considers applicants for new bank facilities in the UK during 2011-2014. As segue to our main analyses, we begin by modelling the use of borrowing-specific business advice. That is, we explore what types of entrepreneurs identify (and act upon) a need for advice before applying for external finance. Following this, we investigate whether accessing business advice helps applicants get satisfactory results at their first attempt of approaching banks. We hypothesize that the riskiness of the business and the diligence of the entrepreneur are good indicators of the probability of seeking advice, and of the ability to successfully exploit advice.

The paper is structured as follows: Section 2 briefly reviews the characteristics of firms or individuals that are linked with advice seeking behaviour. From this we develop our opening two hypotheses. Thereafter, it reviews evidence on the potential effect of advice on loan application success and in mitigating access to finance problems. From this we form our remaining two hypotheses. Section 3 outlines our data and econometric choices; section 4 elaborates our findings; and section 5 discusses the implications of our results for entrepreneurs and policy.

\section{Business advice and SMEs}

Decision makers rarely operate in isolation. Rather, they draw upon internal and external sources of information to analyze a situation and to draft a plan. Entrepreneurs, faced with a dynamic business environment and dense regulations, frequently recognise 
the limits of their expertise. In such circumstances, entrepreneurs must search for additional information and expertise. Evidence on the use of advice by small firms suggests broad use of social networks, business networks, banks and accountants, private professional business services and publicly funded advisory services (McGee \& Sawyerr 2003; Bennett \& Robson 1999; Shaw \& Bennett 1999). Crucially, advice is different from static sources of information such as reports, regulatory documents, and internet content. Advice entails an interactive and iterative process of exchanging information, involving the advice seeker and advice supplier (McGee \& Sawyerr 2003). Advice is a recommendation (Bonaccio \& Dalal 2006) or an influence (Harvey et al. 2000) which is aimed at reducing complexity in the environment. The decision maker may utilize the advice or disregard it (wholly or in part), but in the process of exchanging information a new piece of knowledge or perspective is inevitably transferred. Through decreasing risk and complexity and adding knowledge resources, business advice may improve the prospects of small firms. The empirical evidence typically suggests a positive impact of business advice on small firms' competitiveness (Chrisman \& McMullan 2004; Chrisman et al. 2005; Bennett \& Robson 2000; Robson \& Bennett 2000).

The ability to recognise missing information or the likelihood of having limited confidence in one's decision-making are affected by the entrepreneur's human capital (Scott \& Irwin 2009; Han et al. 2012; Collis \& Jarvis 2002; Johnson et al. 2007; 
Larsson et al. 2003), the level of pre-advice confidence and the accuracy of past decisions (Yaniv 2004), perceptions of the complexity of the environment and of the current challenges (Dyer \& Ross 2008; Trevelyan 2008). Accordingly, advice seeking behaviour and information search activity is influenced by individuals' confidence in their decisions (Yaniv 2004). At opposite extremes, being highly knowledgeable or knowing too little may lead to individuals' overconfidence about their skills and judgment (Bhandari \& Deaves 2006). Forbes (2005) demonstrates that 'comprehensiveness' is associated with overconfidence in entrepreneurs. In this way, we may anticipate a U-shaped relationship between diligence and overconfidence such that the likelihood of being overconfidence initially decreases with diligence, but at very high levels of diligence (i.e. 'comprehensiveness') overconfidence may return. However, the comprehensiveness required is likely to be extensive and, in a mixed sample of small firms, unlikely to be frequently observed. Rather, we hypothesize that better informed and more diligent entrepreneurs are more capable of recognising uncertainty in lending markets and take preventative actions to avoid disappointment. That is, they are more likely to seek external advice before applying:

Hypothesis 1a. Informed and diligent entrepreneurs are more likely to seek advice for their financing needs.

Entrepreneurs' need for external advice is also influenced by the characteristics of their firms. For instance, the size and age of the business are frequently shown to affect the 
probability and intensity of advice seeking (Boter \& Lundström 2005; Dyer \& Ross 2008; Johnson et al. 2007; Robson et al. 2008; Mole et al. 2008). Both size and age may be thought to indicate relative 'riskiness'. Although larger companies are likely to face more complex problems (Johnson et al. 2007), it is the resource constraints associated with smaller size that drives the "liability of smallness" (Aldrich \& Auster 1986). In a similar vein, the related concept of the "liability of newness" is likely to explicate the relationship between age and advice seeking (Stinchcombe \& March 1965). As businesses age, legitimacy improves, knowledge and resources are accumulated and the need for 'routine' external advice diminishes (Bennett \& Robson 2000).

However, firm risk may be strategic as well as structural. Irrespective of age and size considerations, firms adopting specific strategies may face increased risk and uncertainty. Riskier strategies increase perceived environmental uncertainty and, from the perspective of potential funders, information opacity. Entrepreneurs, in turn, must increase their efforts towards environmental screening (McGee \& Sawyerr 2003; Dyer \& Ross 2008). Higher perceived risk is reflected in the behaviour of entrepreneurs. For example, innovative firms are more likely to recognise the need to contact external sources of information to reduce uncertainty (Johnson et al. 2007; Bennett \& Robson 2000). In a similar manner, exporting, as a method of expansion and growth, also increases the complexity of operations and uncertainty (Bennett \& Robson 2000; Johnson et al. 2007). Moreover, growth history may also affect the propensity to seek 
advice (Bennett \& Robson 2000). Growing firms, recognising their higher risk, are likely to perceive of a higher level of difficulty in accessing external financial (Binks \& Ennew 1996; Westhead \& Storey 1997). Indeed, this financing difficulty for higher risk firm may not only be a perception. Recent empirical studies have provided evidence of loan scaling (Freel 2007) or higher pricing (Nitani \& Riding 2013) toward innovative and growing firms. Following this, we hypothesise that increased risk, associated with both structural and strategic factors, reduces entrepreneur's confidence in obtaining external finance, and therefore:

Hypothesis $1 b$. Entrepreneurs whose firms exhibit a higher degree of risk are more likely to seek external sources of information before approaching banks.

Beyond use, measuring the effectiveness of advice and soft support is difficult. Advice is a perishable and intangible good (Bennett \& Robson 1999). Moreover, observing how the advice seeker reacts to the advice is not straightforward. Advisees assess the quality of the given advice based on their perceptions. They weigh the advice against their initial intentions (Bonaccio \& Dalal 2006; Yaniv 2004). They utilize it, or discard it. Indeed, individuals may show reluctance to follow advice even when they know it is true and it is free (Harvey \& Fischer 1997). Nevertheless, in the process of exchanging information, the typical advisee receives reassuring information about their decision (Ramsden \& Bennett 2005). Studies frequently show that entrepreneurs see positive effects from advice and can link the advice to better performance (Bennett \& Robson 
2000; Berry et al. 2006; Boter \& Lundström 2005; Scott \& Irwin 2009). Evidence indicates that business advice may help small firms to survive or grow (Wren \& Storey 2002; Chrisman \& McMullan 2000). Broadly speaking, taking up advice has been shown to benefit advice seekers (Harvey \& Fischer 1997). Advice, even poor quality advice, is thought to decrease complexity (McGee \& Sawyerr 2003) and error variance (Harvey \& Fischer 1997). Both discounting and utilising advice are related to the entrepreneurs' confidence in their knowledge and reasoning. Better informed individuals are more capable of analyzing the information they receive. We speculate that more informed and diligent entrepreneurs are more likely to realize the value of the advice they are offered and utilize or discard it effectively. Accordingly, we hypothesise that:

Hypothesis 2a: More informed and diligent entrepreneurs are more likely to benefit from external advice; with the benefits manifest in a successful financial application.

With respect to the efficacy of the advice in reducing risk; using external advice is likely to lower the perceived level of complexity (Ramsden \& Bennett 2005) and increases the entrepreneur's post-advice confidence (Dyer \& Ross 2008). Accordingly, we hypothesize that the advice sought specifically for external financing will help entrepreneurs reduce the uncertainty associated with their firm and increase the chances of favourable outcome: 
Hypothesis $2 b$. Entrepreneurs with higher risk profiles are more likely to benefit from external advice when applying for external financing.

Seeking advice, valuing, utilizing, or discarding it are not solely dependent upon the decision maker. Rather, it is also affected by structure and the size of the advice market, types of task, rewards system, quality of advice, and trust and power distance between advisees and advisors ( Bennett \& Robson 2000; Berry et al. 2006; Gooderham et al. 2004; Larsson et al. 2003; Mole 2002; Harvey et al. 2000; Mole \& Bramley 2006). Due to data limitations, our study cannot investigate the structure of advice taking-giving systems. Rather we are constrained to focus solely on the entrepreneur. In our study, sources of advice are treated as homogenous. However, we construct an objective index to measure the effectiveness of advice. We call an application a 'success' if the application is new and if funds are offered by the bank and accepted by the entrepreneur at the first attempt - before the entrepreneur and the bank engage in re-negotiating, reduce the amount, or the entrepreneur switches banks. We believe that this measure can help us to understand whether seeking advice can save time and resources and prevent unnecessary stress to the entrepreneur.

\section{Data and methodology}

The data used in this paper is the series of cross-section surveys comprising the Small and Medium Sized Enterprise Finance Monitor (2011-2014) accessed from UK Data Archive (BDRC Continental 2014). The first wave was conducted in 2011 and repeated 
quarterly ${ }^{2}$. In each wave, 5000 telephone interviews were conducted on a broad range of issues related to small firm finance. The respondents to the questionnaire were the persons in charge of making financial decisions within sample firms. Sample businesses are for-profit, non-governmental and independent, with less than 250 employees and less than $£ 25$ Million prior year sales turnover. The screening criteria remained the same during all waves of data collection. The sample is drawn from Dun and Bradstreet and Experian and captures a wide range of businesses across different sectors, sizes, ages, external risk ratings, and locations. In addition, the data provides information on business performance and strategy, planning, and human resource policies. Compared with the UK business population statistics, the dataset is oversampled toward larger firms (BDRC Continental 2015); therefore, analysis without weights would be biased towards those firms.

In our analysis, we used the probability sample weight calculated by BDRC Continental from the first quarter of 2012 to second quarter of 2014. The data, and sampling weight, is provided on a 10 waves rolling basis. The weighting is calculated based on population figures for SMEs across numbers of employees, business sectors, 12 NUTS1 regions, and start-ups (see BDRC Continental, 2015). The total sample size is more than 50,000 observations, which represents more than 4.5 million businesses within the UK. All the presented analyses and statistics in our paper are weighted, unless otherwise stated.

\footnotetext{
${ }^{2}$ The last quarter conducted but not published by this date is second quarter of 2015 .
} 
Given the large size of the dataset, we speculate that there is limited risk of cross sampling. Moreover, if a firm appears more than once in the dataset, as a loan applicant and overdraft applicant in the same year, they are treated as a single firm with identical covariates across independent and control variables.

We divided our sample on the basis of overdraft and loan requests separately. The reasons for requesting each type of facility are likely to differ: overdrafts, trade credit and lines of credit are mainly used to address working capital needs, whereas longer term loans are typically requested for the purchase of premises and equipment (Berger \& Udell 2003). In the unweighted sample, there were 2401 and 4572 firms that applied for, respectively, term loans and overdrafts and, in turn, $25 \%$ and $13 \%$ of these applicants sought advice prior to application. It appears that entrepreneurs perceive greater challenges when they decide to apply for term loans. The survey studied the demand for external financing in the 12 months preceding each wave of the survey. The survey explicitly asks, only from new applicants, whether the entrepreneur has sought external advice before applying for her new loan or overdraft facility ${ }^{3}$. This gave us the opportunity to investigate the characteristics of those managers who look for bankrelated application advice, not general advice. We did not include firms who were asked by banks to re-negotiate the terms of contract, cancel an existing facility, lower or increase a loan or overdraft amount, since the decision to approach the banks was not

\footnotetext{
${ }^{3}$ The text of the question reads: "Did you seek any external advice before applying for your overdraft/loan facility?"
} 
initiated by the entrepreneur. In addition, in the case of existing facilities, both sides are likely to be better informed about the condition of the facility and its riskiness.

Consequently, we prepared two different sub-samples: Loan applicants and overdraft applicants. Since the sample only deals with new applications, the problem of selection bias might exist (we do not observe how non-applicants and banks would behave should the entrepreneurs decided to apply for a facility). To control for selection bias, we hoped to estimate a two-stage Heckman procedure, modelling financial neediness in the first stage. However, from the variables available, it was not possible to meet the exclusion criteria. There are some questions which explore the reasons for seeking finance, however, those questions were only asked of applicants and cannot be used in a two stage analysis. With this in mind, we are cautious in not extending our findings to nonapplicants.

To test hypothesis $1 \mathrm{a}$ and $1 \mathrm{~b}$, we model the probability of seeking advice prior to requesting external finance as a function of characteristics of the entrepreneur and potential sources of application risk alongside with a set of control variables. To investigate the effect of advice in mitigating risk, ideally we would like to employ advice-taking as an independent variable and assess its significance in explaining the probability of obtaining credit. However, since many of the variables hypothesized to influence advice seeking behaviour are also likely to bear on application success, this approach raises conceptual and empirical challenges. To overcome this challenge, one 
might seek to replace advice-seeking with its instrument. However, as is frequently the case in research of this kind, finding suitable instruments was not possible ${ }^{4}$. Accordingly, we chose to split the sample further and regress the probability of successful application for advice seekers and their counterparts separately. This allows us to compare the variables that improve or diminish the probability of application success for firms seeking advice and non-seekers of advice ${ }^{5}$.

\section{Dependent variables}

In the first stage of our analysis, identifying the characteristics of advice seekers, we used a dummy variable equal to 1 if the entrepreneur sought external advice prior to applying for bank finance. As indicated, some applicants were referred to sources of advice by banks after initial rejection. We do not include these applicants as they approached external sources of advice to satisfy their banks, not to identify any potential gap proactively. This operationalisation of advice-seeking remained the same over all analyses.

For the dependent variable used in the second stage of our analysis, we employed a specific definition for application success. We consider an application successful if the bank and entrepreneur agree on a contract at the first attempt. This allows us to consider

\footnotetext{
${ }^{4}$ The pitfalls of using mis-specified two-stage models and invalid or weak instrument are explained by Puhani (2000) and Murray (2006) .

${ }^{5}$ We also tested for multicollinearity problem by calculating Variance Inflation Factor (VIF). None of the variables showed VIFs greater than 10.
} 
the effect of advice seeking prior to approaching banks and to control for the effect of appealing, renegotiating, re-applying, or switching banks. For this reason, our rate of successful application is lower than the ultimate success rate (unweighted, $62 \%$ and $75 \%$ success rate for, respectively, loan and overdraft based on our definition; and $80 \%$ and $88 \%$ for ultimate success defined by the survey conductor). To test the hypotheses, we estimate Probit regression models, since our dependent variables are binary.

\section{Independent variables}

Our study investigates the effect of perceived knowledge gaps and business risk on advice seeking behaviour and on the usefulness of advice sought. We incorporated different measures to proxy these two elements. Firstly, we hypothesize that diligent entrepreneurs are more likely to recognise knowledge gaps, seek external advice (H1a) and use the advice effectively (H2a). It seems clear that entrepreneurs require some degree of absorptive capacity to realize the benefits of advice (Gooderham et al. 2004). To measure diligence, we first consider financial training. We speculate that training in financial management helps entrepreneurs understand external financing requirements and take the necessary steps to meet those requirements. Beyond this, we conjecture that if the long term plan of the business is clear, the entrepreneur is more likely to know the resources needed for development and act to acquire these. In line with this idea, we also use a dummy variable indicating the production of regular accounting reports. Generating systematic accounting information should help the owner identify sources of 
risk and to take the necessary steps to mitigate these. Periodic reporting is the most used indicator of the financial wellbeing of entrepreneurs and often signals a good relationship with lenders (Collis \& Jarvis 2002).

Our second concern is with the effect of potential business risk on the propensity to seek advice $(\mathrm{H} 1 \mathrm{~b})$ and on the effectiveness of advice in mitigating risk (H2b). In the first instance, we use innovation as an indicator of riskiness. Innovation is an essentially speculative strategy, with innovative firms committing resources to an uncertain outcome. Past research on the financing of innovative small firms has shown them to be less successful in loan markets relative to their less innovative peers (Freel 2007). As Mina and colleagues note (2013, p. 894), “uncertain innovation activities negatively affect the supply of finance, in line with the expectation that businesses undertaking risky projects will incur higher external costs of capital and will have access to suboptimal levels of financial resources". In our analysis, a firm is innovative if they declared they developed a new product or service and/or significantly improved an aspect of the business in the three years prior to the survey.

Our second indicator of potential business risk is exporting. In the face of imperfect access to information, foreign market entry becomes a particularly risky and uncertain undertaking (Bennett \& Robson 2000; Hessels \& Terjesen 2010)(Bennett \& Robson 2000; Hessels \& Terjesen 2010). We identify a firm as an exporter if they declare that 
they sell products or services outside of the UK. Ideally, we would also like to capture the effect of firm growth on perceived riskiness (see, for example, Rostamkalaei \& Freel 2016). Indeed, data on the growth history of firms were available to us; however, the data were highly collinear with business age. That is, the majority of firms which experience substantial growth in sale turnover were the youngest ones. Accordingly, we only include the age of the business in our models.

We also proxy business risk by firm size and age: reasoning that older and larger firms have improved access to resources, which lower their risk profiles. In addition, we expect younger, less experienced firms (and their entrepreneurs) to have accumulated less knowledge; therefore, they are expected to be more likely to perceive higher risks with their applications. Firm size is measured by number of employees and firm age by the years since business establishment. Both variables are measured categorically.

Our next measures relate to the relationship of the applicants with their banks. It has long been argued that established relationships between banks and their customers provide the basis for the exchange and accumulation of better quality data about entrepreneurs and the prospects of their businesses; leading to a decrease in the information asymmetry that is thought to mark small firm-bank relationships (Binks \& Ennew 1996). In this way, relational banking may increase small firms' access to bank facilities or, at least, lead to better terms of contract. For instance, in a study of the 
effect of bank provided business advice on the financial condition of small firms, Han et al (2012) found that better relationships with banks lowered the entrepreneur's perceptions of difficulties in accessing finance. In line with this, we speculate that applying to a firm's main bank will lower perceived risk for both the entrepreneur and the bank. However, we observe that almost all overdraft applicants applied to their main banks (table 1). For this reason, we excluded this variable from our overdraft applications estimations. In addition, we are able to identify first time applicants. This group are expected to know less about the application procedures and banks' lending criteria, and are more likely to seek advice prior to applying. We also control for the amount of facility sought; with the expectation that larger amounts signal more risk to both banks and entrepreneurs.

In evaluating the effectiveness of advice, we add one additional variable. For both term loans and overdrafts, we identify the reason(s) why the money was requested. We speculate that the reasons funds are sought may affect application outcome. For example, if the loan is sought to purchase assets, the risk taken on by the bank would be lower than a situation where the funds are sought to support firm growth. In the former case, firms can pledge the purchased asset to insure the loan; in the latter, money is used to fund a risky activity with an uncertain outcome.

Relatedly, in assessing the riskiness of the business, the ability of firms to provide collateral to partially insure the loan and reduce moral hazard has been widely discussed 
in the literature (e.g. Berger \& Udell 1998; Parker 2002). Ideally, we would hope to include some measure of the firm's ability to pledge collateral, such as firm's assets or entrepreneur's personal wealth. Unfortunately, this information was not available. We hope to capture some effect of asset availability by controlling for industry and business age.

\section{Control variables}

In order to estimate the unique effects of diligence and riskiness on the behaviour of entrepreneurs and banks, it is important to account for other possible influences on advice-seeking behaviour and application success. To this end, we include a number of control variables in our models. Firstly, we include a variable that indicates the location of the firm, since the density and quality of advisory services may differ and past research has shown that small firms typically use local providers for business advice (Bennett et al. 2000). The variable takes the form of a categorical variable that records whether firms were located in the dominant economies of London or the Southeast of the UK, with the rest of the UK acting as a reference group. We also include industry sector, since the objective and perceived risk of businesses may differ across different sectors (Michelacci \& Schivardi 2013). Moreover, some industries may draw upon their networks more for gathering external information. In addition, we incorporate a dummy variable equal to 1 if the business is mainly run by a woman (i.e. more than $50 \%$ of the firm belongs to a woman). Gender is a 'usual suspect' in studies concerned with small 
firms and their banks (e.g. Orser et al. 2006) and advice seeking (Mole et al. 2008). We control for the legal status of the business on the grounds that the number of proprietors may influence the need to seek external advice and the likelihood of application success (Demirguc-Kunt et al. 2006). Finally, since the survey was conducted after the credit crunch of 2008 and the subsequent 'healing' period (Cowling et al. 2012), we do not expect the perceived riskiness of the businesses would differ across 2011-2014. However, as Cowling, Liu, and Ledger (2012, p.796) note, "For banks and small businesses, the way they react to a recessionary environment is quite different and not synchronised". Accordingly, we control for the year in which each wave of the survey was conducted to account for the potential psychic effect of the credit crunch - viz. banks scaling down available credit and small businesses' reluctance to approach banks.

\section{Descriptive statistics}

Table 1 presents descriptive statistics for the variables of interest used in our analysis. The data in the table are weighted. Accordingly, the bias towards larger firms, present in the unweighted data, is not apparent here. More than half of the firms in the weighted sample are zero-employees businesses. While $74 \%$ of small firms in the UK are zeroemployee firms, only $20 \%$ of these firms were considered in the sampling protocol (BDRC Continental 2014). This difference illustrates why it is important to consider sampling weight in our analysis. Beyond size, $22 \%$ and $17 \%$ of loan and overdraft applicants were less than two years old. These figures approach the $20 \%$ estimation 
reported by the survey conductor for the share of start-ups in UK small businesses population.

\section{TABLE1}

In the case of both loan and overdraft applicants, $50 \%$ of firms use regular accounting reports and more than $40 \%$ have formal business plans. Further, around $30 \%$ of entrepreneurs have been trained to manage their business' financial tasks. In terms of innovators and exporters, given the definitions employed, half the sample report being innovators, whereas only 1 in 10 report exporting.

\section{Results}

\section{Advice Seeking}

Turning to our main results, Table 2 reports the results of our first stage analysis weighted Probit models estimating the probability of bank-specific advice seeking behaviour among loan and overdraft applicants. In the first instance, we hypothesised that better informed firms (proxied by regular financial reporting, formal business planning and financial training) would be more likely to seek advice prior to approaching banks for funds. In the loan panel, only formal business planning is associated with the increased probability of advice seeking. However, for overdraft funding, preparing regular accounting reports and the presence of a formal business plan both increase the probability of advice seeking. We take these results to partially confirm hypothesis 1a; which speculated that more diligent entrepreneurs would be 
more likely to perceive information/resource gaps and seek advice before requesting external finance. To rephrase, among applicants to banks, those entrepreneurs who show some degree of professionalism through regular accounting reports and preparing business plan are more likely to realize a gap between what they know and what they need to know before completing a bank application.

\section{TABLE2}

Hypothesis $1 \mathrm{~b}$ held that riskier firms would be more likely to seek advice - with riskiness measured by exporting and innovation activities; by the age and size of the business; by applications to other than the firm's main bank; by first time applications; and by the amount of funds requested. Our results suggest that innovative firms were more likely to seek advice prior to approaching banks for both term loans and overdraft funding. Exporting also positively associates with the probability of advice-seeking prior to applications for overdraft funding. We interpret these findings to show that entrepreneurs pursuing riskier strategies appreciate the greater risk to banks and increase their information-seeking/uncertainty-reducing efforts. Similarly, the coefficients on business age categories for both loan and overdraft applications indicate that as firms age, the probability of seeking external advice fall. In the same vein, as firms get larger, they are likely to accumulate more tangible and intangible assets and build relationship with their banks, such that they perceive fewer knowledge gaps and less risk with respect to bank finance. In this way, we expected firm size to be 
negatively associated with the probability of advice-seeking. Our results, however, only provide partial support: For overdraft applications, firms with more than 50 employees are less likely to seek finance advice than zero employee firms.

Continuing with the hypothesised influence of perceived riskiness on advice-seeking behaviour; the amount of facility sought is also a significant predictor of the likelihood of advice-seeking. For both loan and overdraft applicants, as the amount of requested facility increases, the entrepreneur's likelihood of engaging with external sources of information and advice increases. In general, these results support hypothesis $1 \mathrm{~b}$ in indicating that riskier firms were more likely to seek advice prior to approaching banks for finance; with this holding for a broad array of indicators of risk.

\section{Benefits of Advice}

Turning to the second stage of our analysis: Table 3 displays the results of weighted Probit models of the probability of successful loan and overdraft applications for advice seekers and non-seekers. As mentioned, our definition of successful application is different from ultimate success in securing external funding. If bank and entrepreneur agree on terms of contract at the first attempt, we call that application a successful one. Considering the variables that are used to indicate the entrepreneur's diligence, the data provide no support for hypothesis $2 \mathrm{a}$. Indeed, some results appear contrary to our speculations. For example, taking advice decreases the probability of accessing overdraft funding for applicants with financial training. It also decreases the probability 
of access to loans for applicants who generate regular accounting reports, while this measure has a positive influence on application success in the non-advice seeking group. The only positive significant effect of advice exists for overdraft applicants who had a business plan. These counter-intuitive results are certainly intriguing. One possible explanation might relate to the effect of advice in increasing the confidence of entrepreneurs. In such circumstances, confident entrepreneurs, with additional knowledge, are less likely to accept the bank's initial offer and more likely to engage in negotiation (in which case they would be erroneously classed as 'unsuccessful' here). If we use final funding outcomes as a measure of success, the negative effect of regular accounting reports does not exist. It is also possible that, while more diligent entrepreneurs are in a better position to realize the riskiness of their business and to seek advice, ultimately the advice cannot wholly ameliorate the risks involved. Whilst it is useful to speculate, these relationships would appear to warrant further research.

\section{TABLE3}

Turning to measures of risk and hypothesis $2 b$, we find no evidence that exporting is a significant variable in explaining the probability of successful applications in both advice-seeking and non-seeking models. On the other hand, the negative effect of innovation on application success is absent from advice-seeking models and, indeed, is positively associated with successful loan applications. In both types of application, advice-seeking (and taking) benefits innovative firms. 
Our results also suggest that advice-seeking reduces the negative effects of smaller size and younger age on application success. For both overdraft and loan applications in the non-advice seeking group, size and age of the business are significant factors in explaining the probability of successful application. As one would expect, smaller and younger firms occupy unfavourable positions in lending markets in comparison to their better resourced and experienced counterparts. However, in our advice-seeking group, age is no longer a significant predictor of success. In a similar way, advice seeking seems to mitigate the liability of smallness when applying for overdraft funds although the effect on loan applications is only partial: In loan applications, the negative effect of size on smaller firms is removed relative to firms with 1 to 10 employees. However, firms with more than 10 employees are still more likely to achieve a successful outcome than zero-employee firms. In general, advice helps to remove the positive significant effect of age and size in applications for bank finance. Advice taking may have an important role to play in bridging the knowledge gaps of micro firms and start-ups and help them overcome 'liabilities' associated with newness and smallness. Moreover, as anticipated, loan applicants are significantly less likely to enjoy initial application success when they apply exclusively to their main banks. However, this effect turns positive when applicants seek advice beforehand. It seems that advice may increase the entrepreneur's knowledge of credit markets and, in consequence, their confidence in their ability to secure a loan from their main bank. Advice taking also 
increases the chance of a successful application for larger loans. In the advice-seeking group, larger applications have a better chance of being successful. In the non-advice seeking group, the size of the facility is not associated with success. Finally, in the case of overdraft applications, first time applicants are significantly less likely to be successful; and advice-seeking does not alter this observed relationship.

Taken together, we interpret the results to indicate support for hypothesis b2. That is, to the extent that advice-seeking ameliorates the risks associated with innovativeness, age, size and single sourcing, it improves the prospects of small firms. This is also in line with the reported association between use of advice and lower level of perceived difficulty in raising external finance (Scott \& Irwin 2009).

To summarize both stages of analysis; we find some evidence that more diligent entrepreneurs are more likely to seek external advice when they decide to apply for bank facilities. However, they are not more likely to benefit from the advice sought in terms of improved chances of application success. Of course, this need not be interpreted as 'no effect'. Rather, advice-seeking could result in increased knowledge and confidence and an unwillingness to accept the first offer. Unfortunately, our data does not allow us to explore this further and we are constrained to simply note the absence of an association with initial funding outcomes.

On the risk measures, we find that innovative firms are more likely to seek advice when the entrepreneur decides to apply for a bank loan and to benefit from the advice sought. 
Advice also improves the prospects of firms applying solely to their main banks. We speculate that this revolves around removing the negative effect of information restricted by the main bank and increasing the chance of successful application. Our strongest findings, however, relate to the effect of advice in attenuating difficulties in obtaining bank facilities for newer firms and, to lesser degree, smaller firms. Younger firms across all models were shown to be the main consumers of pre-application advice and to benefit from the advice sought. In other words, newer and smaller firms that have accessed external advice appear to be more 'debt ready' than their counterparts who eschew advice. They are able to obtain what they need in shorter time, with less physic pressure, allowing the entrepreneur to spend more of their limited time and energy on developing the early stage firm.

\section{Concluding Remarks}

To date, the literature on small firms and their banks has been dominated by concerns with funding outcomes, with some limited work on supply-side lending technologies (Cowling et al. 2012; Berger \& Black 2011). The former often models application success as a function of a vector of firm and/or entrepreneur characteristics; to identify turn down rates or, more recently, adverse loan conditions among specific sub-sets of small firms (e.g. innovative, growing or exporting firms) or entrepreneurs (e.g. firms owned by women or visible minorities). This approach treats firms as islands of 
decision-making, which sits ill with longstanding evidence on the extensive use of external sources of advice by small firms (Bennett \& Robson 1999).

Although small firms may be susceptible to credit rationing, this phenomenon is less likely to exist in the long run when the finance market for small firms is in equilibrium: i.e. there is a price at which the supply and demand for credit are equal. However, the price mechanism works under several conditions. For small firms "the key assumptions most likely to be contravened are those of perfect information and the absence of externalities" (Storey 2003, p.476). Imperfect information can give rise to perceived riskiness and leads to risk overestimation. Although there is limited evidence of broadbased credit rationing, with turndown rates historically low, there is some evidence that particular groups of small firms fare less well (e.g. the very young and small, innovative firms and growing firms). These groups are thought to be 'riskier'. And, since many of the sources of risk are thought to be intractable, the typical response is to call for supply-side interventions. For example, policies such as Loan Guarantee Schemes (LGS) reduce the objective risk to the lender by transferring much of the default risk to the government, encouraging the lender to fund projects which are not likely to secure debt without government intervention.

However, a focus on supply-side interventions appears to ignore the possibility that the risk involved is a combination of both objective and subjective risk. The former may 
well be intractable (and amenable only to transference), but the latter is surely not. Rather, it is likely to be a function of information-asymmetries and may well be responsive to demand-side actions. One example of such effort is the "investment readiness" initiatives in the UK, which aim to prepare firms for equity financing (Mason \& Harrison 2001). There may also exist scope for better equipping small firms for lending markets (Freel 2007). These efforts may help small, high-risk firms to reduce their perceived riskiness and increase their chance of accessing debt with less effort, in shorter time, and on more favourable terms.

In the current study, we are interested in the extent to which a particular form of demand-side action - advice seeking - acts to reduce identified liabilities in loan and overdraft applications to improve the prospects of small firms. Encouraging SMEs to access external advice has been a central plank of enterprise policy in most developed economies (Cumming \& Fischer 2012). In the UK, for instance, the government has sponsored the creation of a "mentoring gateway" (www.mentorsme.com), which seeks to link entrepreneurs with potential sources of advice in the public and private sectors. Outside of the UK, McCann and Ortega-Argilés (2016, p. 546), in their review of European enterprise policy, suggest that for "small and micro-enterprises, in particular, basic business advice may be the single most cost-effective form of support". However, the advice offered under the ambit of enterprise policy is typically not specific to bank 
finance and, where it touches on financing at all, it is explicitly concerned with “investment readiness" (e.g. Department for Business, Innovation \& Skills 2011, 7).

Drawing upon data from the UK SME Finance Monitor (BDRC Continental 2014), we investigate the link between borrowing-specific business advice and loan application success. Initially, we explore the extent to which diligence and risk associate with advice-seeking. In both cases, we observe that more diligent entrepreneurs and those leading riskier businesses are more likely to seek advice.

Thereafter, we speculate that the benefits of advice-seeking will be greatest among diligent and risky businesses. Our results do not support the former; but strongly support the later. The prospects of innovative, new and micro firms are enhanced following lending-specific advice. The results suggest that demand-side efforts aimed at alleviating risk may be fruitful. In other words, advice-taking for the purpose of external financing may mitigate the 'liability of smallness and newness' and liabilities associated with innovativeness.

Additional evidence of the positive impact of advice is important. A UK report (BMG Research 2011), exploring barriers to the take up and use of business advice, noted that "[w] ith regards to the various categories of market failure, doubts about the benefits and value of assistance in relation to its cost appeared to be the most common form of market failure" (p. 71). This echoes Storey's (Storey 2003) earlier assertion that "[s]mall business owners do not realise the private benefits of obtaining expert advice 
from "outside" specialists". That our results suggest a positive impact of advice on bank financing provides practical guidance to entrepreneurs.

\section{Funding}

The author(s) received no financial support for the research, authorship, and/or publication of this article. 
Table 1. Descriptive statistics (weighted) - as percentage of loan or overdraft applicants

\begin{tabular}{|c|c|c|c|c|c|}
\hline & Loan & Overdraft & & Loan & Overdraft \\
\hline Advice seekers & $20 \%$ & $10 \%$ & & & \\
\hline $\begin{array}{l}\text { Successful } \\
\text { application }\end{array}$ & $47 \%$ & $63 \%$ & $\begin{array}{l}\text { Applicants } \\
\text { main bank }\end{array}$ & $89 \%$ & $97 \%$ \\
\hline $\begin{array}{l}\text { Financial } \\
\text { training }\end{array}$ & $30 \%$ & $28 \%$ & Age of Business & & \\
\hline Business plan & $47 \%$ & $42 \%$ & start-up & $22 \%$ & $17 \%$ \\
\hline Accounting & $51 \%$ & $50 \%$ & $2-5$ yrs & $22 \%$ & $22 \%$ \\
\hline exporter & $11 \%$ & $10 \%$ & $6-10$ yrs & $27 \%$ & $28 \%$ \\
\hline Innovation & $50 \%$ & $50 \%$ & $>15$ yrs & $29 \%$ & $33 \%$ \\
\hline $\begin{array}{ll}\text { first } & \text { time } \\
\text { applicant } & \end{array}$ & $46 \%$ & $29 \%$ & Size & & \\
\hline $\begin{array}{l}\text { Amount of } \\
\text { facility }\end{array}$ & & & Zero employees & $59 \%$ & $57 \%$ \\
\hline $\begin{array}{l}\text { Less than } \\
10 \mathrm{k}\end{array}$ & $41 \%$ & $62 \%$ & 1-9 employees & $34 \%$ & $37 \%$ \\
\hline $10 \mathrm{~K}-100 \mathrm{~K}$ & $44 \%$ & $32 \%$ & 10-49 employees & $6 \%$ & $6 \%$ \\
\hline$>100 \mathrm{k}$ & $15 \%$ & $6 \%$ & $>50$ employees & $1 \%$ & $1 \%$ \\
\hline
\end{tabular}


Table 2. Weighted Probit model for the effects of diligence and risk on the probability of advice seeking

\begin{tabular}{|c|c|c|c|c|}
\hline \multirow[b]{2}{*}{ DV Advice sought=1 } & \multicolumn{2}{|l|}{ Loan } & \multicolumn{2}{|l|}{ Overdraft } \\
\hline & Coeff & S.E & Coeff & S.E \\
\hline Financial training (yes $==1$ ) & 0.124 & 0.154 & 0.154 & 0.114 \\
\hline Business Plan (yes $==1$ ) & $0.314^{* *}$ & 0.135 & $0.271^{* *}$ & 0.118 \\
\hline $\begin{array}{lll}\begin{array}{l}\text { Regular } \\
\text { (yes }==1)\end{array} & \text { accounting } & \text { reports } \\
\end{array}$ & 0.0768 & 0.145 & $0.414^{* * *}$ & 0.144 \\
\hline Export (yes $==1)$ & 0.269 & 0.227 & $0.234^{* *}$ & 0.115 \\
\hline Innovation $($ yes $==1)$ & $0.345^{\star *}$ & 0.139 & 0.00513 & 0.113 \\
\hline First time applicant $(y e s==1)$ & -0.0461 & 0.141 & $0.281^{* *}$ & 0.135 \\
\hline Application to main bank (yes $==1$ ) & -0.0115 & 0.204 & & \\
\hline \multicolumn{5}{|l|}{ Amount sought (ref: $<10 \mathrm{k})$} \\
\hline $10-100 \mathrm{~K}$ & $0.367^{\star \star}$ & 0.164 & 0.151 & 0.115 \\
\hline$>100 \mathrm{~K}$ & $1.122^{\star \star \star}$ & 0.184 & $0.414^{\star \star}$ & 0.164 \\
\hline \multicolumn{5}{|l|}{ business age (ref: start-ups) } \\
\hline $2-5$ yrs & -0.225 & 0.201 & -0.259 & 0.181 \\
\hline $6-15 \mathrm{yrs}$ & $-0.813^{\star \star \star}$ & 0.221 & -0.269 & 0.181 \\
\hline$>15$ yrs & $-0.506^{\star \star}$ & 0.221 & $-0.538^{\star \star \star}$ & 0.178 \\
\hline \multicolumn{5}{|l|}{ Size (ref: 0 employees) } \\
\hline $1-9$ emps & 0.196 & 0.158 & -0.0324 & 0.138 \\
\hline $10-49$ emps & 0.00966 & 0.215 & -0.0152 & 0.174 \\
\hline$>50$ emps & -0.252 & 0.261 & $-0.380^{*}$ & 0.214 \\
\hline Business run by female & $0.337^{* *}$ & 0.151 & 0.0343 & 0.11 \\
\hline \multicolumn{5}{|l|}{ Location (ref=rest of the UK) } \\
\hline London & 0.234 & 0.21 & -0.173 & 0.132 \\
\hline South East & 0.0666 & 0.184 & 0.00858 & 0.156 \\
\hline \multicolumn{5}{|l|}{$\begin{array}{l}\text { Sector(ref=community and personal } \\
\text { services) }\end{array}$} \\
\hline Agriculture & 0.142 & 0.244 & $0.406^{* *}$ & 0.194 \\
\hline Manufacturing & -0.0456 & 0.305 & 0.117 & 0.234 \\
\hline Construction & -0.0156 & 0.256 & 0.147 & 0.204 \\
\hline Services & 0.143 & 0.218 & 0.00853 & 0.176 \\
\hline Real Estate & 0.0857 & 0.24 & 0.249 & 0.184 \\
\hline Legal (sole proprietorships $==1$ ) & 0.258 & 0.164 & $-0.364^{\star \star \star}$ & 0.14 \\
\hline \multicolumn{5}{|l|}{ Wave $(r e f==2011)$} \\
\hline 2012 & -0.233 & 0.165 & -0.109 & 0.137 \\
\hline 2013 & -0.0768 & 0.193 & -0.0187 & 0.144 \\
\hline 2014 & -0.00959 & 0.352 & 0.0676 & 0.231 \\
\hline Constant & $-1.624^{\star \star \star}$ & 0.343 & $-1.452^{\star \star \star}$ & 0.291 \\
\hline Observations & 1759 & & 3955 & \\
\hline p-value & 0 & & 0 & \\
\hline Summer's D & $66 \%$ & & $74 \%$ & \\
\hline
\end{tabular}


Table 3. Weighted Probit model for the effects of advice on the probability of successful application

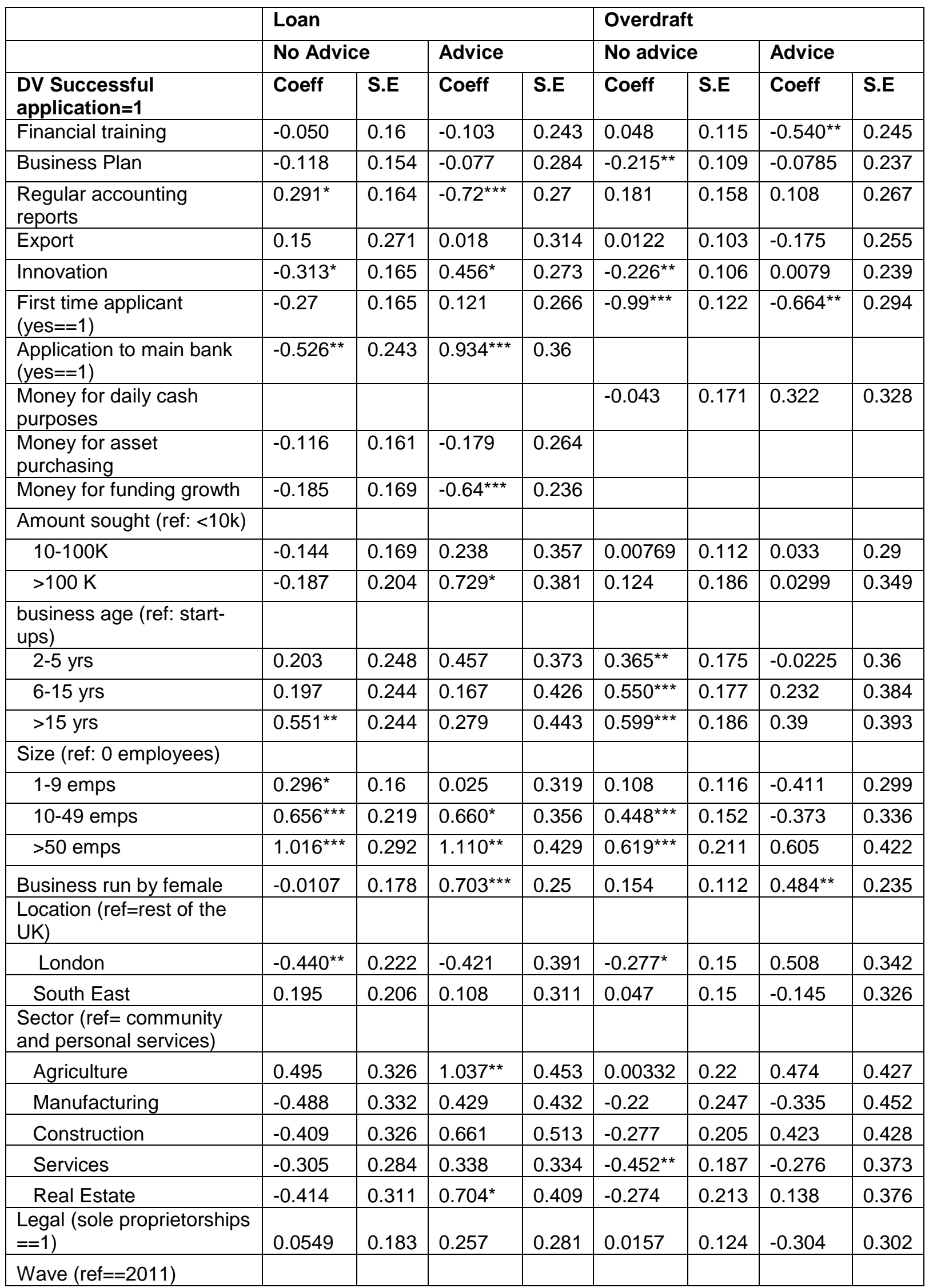




\begin{tabular}{|l|l|l|l|l|l|l|l|l|}
\hline 2012 & 0.227 & 0.21 & -0.0468 & 0.29 & -0.136 & 0.122 & -0.0431 & 0.273 \\
\hline 2013 & -0.0923 & 0.222 & 0.242 & 0.333 & $-0.229^{*}$ & 0.129 & -0.379 & 0.284 \\
\hline 2014 & 0.513 & 0.333 & $1.042^{*}$ & 0.546 & -0.36 & 0.256 & -0.41 & 0.557 \\
\hline Constant & 0.402 & 0.521 & $-1.938^{\star *}$ & 0.771 & $0.725^{\star \star}$ & 0.330 & 0.516 & 0.67 \\
\hline Observations & 1228 & & 416 & & 3312 & & 491 & \\
\hline$p$ & 0.0 & & 0 & & 0 & & 0.00363 & \\
\hline Summer's D & $72 \%$ & & $58 \%$ & & $77 \%$ & & $68 \%$ & \\
\hline${ }^{* * *} p<0.01,{ }^{* *} p<0.05,{ }^{*} \mathrm{p}<0.1$ & \multicolumn{7}{|l|l|l|}{} \\
\hline
\end{tabular}




\section{Reference:}

Aldrich, H.E. \& Auster, E., 1986. Even dwarfs started small: Liabilities of age and size and their strategic implications. Research in organizational behavior, (8), pp.165198.

BDRC Continental, 2014. Small- and Medium-Sized Enterprise Finance Monitor: Waves 1-11, 2011-2013. Available at: http://dx.doi.org/10.5255/UKDA-SN-6888-9 [Accessed May 29, 2015].

BDRC Continental, 2015. SME Finance Monitor Q4 2014: An independent report by BDRC Continental, Feb 2015.

Beck, T., Demirgüç-Kunt, A. \& Singer, D., 2013. Is small beautiful? Financial structure, size and access to finance. World Development, 52, pp.19-33.

Bennett, R.J., Bratton, W.A. \& Robson, P.J.A., 2000. Business advice: the influence of distance. Regional Studies, 34(9), pp.813-828.

Bennett, R.J. \& Robson, P.J.A., 2000. The use and impact of business advice by SMEs in Britain: an empirical assessment using logit and ordered logit models. Applied

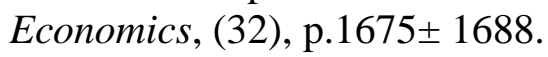

Bennett, R.J. \& Robson, P.J.A., 1999. The use of external business advice by SMEs in Britain. Entrepreneurship \& Regional Development, 11(2), pp.155-180.

Berger, A.N. \& Black, L.K., 2011. Bank size, lending technologies, and small business finance. Journal of Banking \& Finance, 35(3), pp.724-735.

Berger, A.N., Frame, W.S. \& Miller, N.H., 2005. Credit Scoring and the Availability, Price, and Risk of Small Business Credit. Journal of Money Credit and Banking, 37(2), pp.191-222.

Berger, A.N. \& Udell, G.F., 2006. A more complete conceptual framework for SME finance. Journal of Banking \& Finance, 30(11), pp.2945-2966.

Berger, A.N. \& Udell, G.F., 2003. Small Business and Debt Finance. In Z. J. Acs \& D. B. Audretsch, eds. Handbook of Entrepreneurship Research. Great Britain: Kluwer Academic Publisher, pp. 299-328. Available at: http://link.springer.com/chapter/10.1007/0-387-24519-7_13.

Berger, A.N. \& Udell, G.F., 1998. The economics of small business finance: The roles of private equity and debt markets in the financial growth cycle. Journal of Banking \& Finance, 22, pp.613-673. 
Berry, A.J., Sweeting, R. \& Goto, J., 2006. The effect of business advisers on the performance of SMEs. Journal of Small Business and Enterprise Development, 13(1), pp.33-47.

Bhandari, G. \& Deaves, R., 2006. The Demographics of Overconfidence. Journal of Behavioral Finance, 7(1), pp.5-11.

Binks, M.R. \& Ennew, C.T., 1996. Growing Firms and Credit Constraint. Small Business Economics, (8), pp.17-25.

Blackburn, R.A., 2016. Government, SMEs and entrepreneurship development: Policy, practice and challenges, Routledge.

BMG Research, 2011. Research to understand the barriers to take up and use of business support. Available at: https://www.gov.uk/government/publications/research-tounderstand-the-barriers-to-take-up-and-use-of-business-support.

Bonaccio, S. \& Dalal, R.S., 2006. Advice taking and decision-making: An integrative literature review, and implications for the organizational sciences. Organizational Behavior and Human Decision Processes, 101(2), pp.127-151.

Boter, H. \& Lundström, A., 2005. SME perspectives on business support services: The role of company size, industry and location H. Matlay, ed. Journal of Small Business and Enterprise Development, 12(2), pp.244-258.

Canton, E. et al., 2013. Perceived credit constraints in the European Union. Small Business Economics, 41(3), pp.701-715.

Chrisman, J.J., McMullan, E. \& Hall, J., 2005. The influence of guided preparation on the long-term performance of new ventures. Journal of Business Venturing, 20(6), pp.769-791.

Chrisman, J.J. \& McMullan, W., 2004. Outsider assistance as a knowledge resource for new venture survival. Journal of Small Business Management, 42(3), pp.229-244.

Chrisman, J.J. \& McMullan, W.E., 2000. A Preliminary Assessment of Outsider Assistance as a Knowledge Resource: The longer-term Impact of New Venture Counselling. Entrepreneurship Theory and Practice, 24(3), pp.37-54.

Collis, J. \& Jarvis, R., 2002. Financial information and the management of small private companies. Journal of Small Business and Enterprise Development, 9(2), pp.100110.

Cowling, M., Liu, W. \& Ledger, A., 2012. Small business financing in the UK before and during the current financial crisis. International Small Business Journal, 30(7), pp.778-800. 
Cumming, D.J. \& Fischer, E., 2012. Publicly funded business advisory services and entrepreneurial outcomes. Research Policy, 41(2), pp.467-481.

Demirguc-Kunt, A., Love, I. \& Maksimovic, V., 2006. Business environment and the incorporation decision. Journal of Banking \& Finance, 30(11), pp.2967-2993.

Department for Business, Innovation \& Skills, 2011. BIGGER, BETTER BUSINESS: Helping small firms start, grow and prosper. Available at: https://www.gov.uk/government/uploads/system/uploads/attachment_data/file/32 225/11-515-bigger-better-business-helping-small-firms.pdf.

Dyer, L.M. \& Ross, C.A., 2008. SEEKING ADVICE IN A DYNAMIC AND COMPLEX BUSINESS ENVIRONMENT: IMPACT ON THE SUCCESS OF SMALL FIRMS. Journal of Developmental Entrepreneurship, 2(13), pp.133149.

Forbes, D.P., 2005. Are some entrepreneurs more overconfident than others? Journal of Business Venturing, 20(5), pp.623-640.

Freel, M. et al., 2010. The latent demand for bank debt: characterizing "discouraged borrowers." Small Business Economics, 38(4), pp.399-418.

Freel, M.S., 2007. Are Small Innovators Credit Rationed? Small Business Economics, 28(1), pp.23-35.

Gooderham, P.N. et al., 2004. Accountants as Sources of Business Advice for Small Firms. International Small Business Journal, 22(1), pp.5-22.

Han, L. et al., 2012. The use and impacts of bank support on UK small and medium-sized enterprises. International Small Business Journal. Available at: http://isb.sagepub.com/content/early/2012/09/10/0266242612455008.abstract [Accessed January 21, 2014].

Harvey, N. \& Fischer, I., 1997. Taking Advice: Accepting Help, Improving Judgment, and Sharing Responsibility. Organizational Behavior and Human Decision Processes, 70(2), pp.117-133.

Harvey, N., Harries, C. \& Fischer, I., 2000. Using Advice and Assessing Its Quality. Organizational Behavior and Human Decision Processes, 81(2), pp.252-273.

Hessels, J. \& Terjesen, S., 2010. Resource dependency and institutional theory perspectives on direct and indirect export choices. Small Business Economics, 34(2), pp.203-220.

Johnson, S., Webber, D.J. \& Thomas, W., 2007. Which SMEs use external business advice? A multivariate subregional study. Environment and Planning A, 39(8), pp.1981-1997. 
Kent, P., 1994. Management advisory services and the financial performance of clients. International Small Business Journal, 12(4), pp.45-58.

Kirschenmann, K., 2016. Credit rationing in small firm-bank relationships. Journal of Financial Intermediation, 26, pp.68-99.

Kon, Y. \& Storey, D.J., 2003. A Theory of Discouraged Borrowers. Small Business Economics, 21(1), pp.37-49.

Kremp, E. \& Sevestre, P., 2013. Did the crisis induce credit rationing for French SMEs? Journal of Banking \& Finance, 37(10), pp.3757-3772.

Larsson, E., Hedelin, L. \& Garling, T., 2003. Influence of Expert Advice on Expansion Goals of Small Businesses in Rural Sweden. Journal of Small Business Management, 41(2), pp.205-212.

Lee, N., Sameen, H. \& Cowling, M., 2014. Access to finance for innovative SMEs since the financial crisis. Research Policy, 44(2), pp.370-380.

Mason, C.M. \& Harrison, R.T., 2001. "Investment Readiness": A Critique of Government Proposals to Increase the Demand for Venture Capital. Regional Studies, 35(7), pp.663-668.

McCann, P. \& Ortega-Argilés, R., 2016. Smart specialisation, entrepreneurship and SMEs: issues and challenges for a results-oriented EU regional policy. Small Business Economics, 46(4), pp.537-552.

McGee, J.E. \& Sawyerr, O.O., 2003. Uncertainty and Information Search Activities: A Study of Owner-Managers of Small High-Technology Manufacturing Firms. Journal of Small Business Management, 41(4), pp.385-401.

Michelacci, C. \& Schivardi, F., 2013. Does Idiosyncratic Business Risk Matter for Growth? Journal of the European Economic Association, 11(2), pp.343-368.

Mina, A., Lahr, H. \& Hughes, A., 2013. The demand and supply of external finance for innovative firms. Industrial and Corporate Change, 22(4), pp.869-901.

Mole, K., 2002. Business Advisers' Impact on SMEs: An Agency Theory Approach. International Small Business Journal, 20(2), pp.139-162.

Mole, K. et al., 2008. Differential gains from Business Link support and advice: a treatment effects approach. Environment and Planning C: Government and Policy, 26(2), pp.315-334.

Mole, K.F. \& Bramley, G., 2006. Making Policy Choices in Nonfinancial Business Support: An International Comparison. Environment and Planning C: Government and Policy, 24(6), pp.885-908. 
Nitani, M. \& Riding, A., 2013. Growth, R\&amp;D intensity and commercial lender relationships. Journal of Small Business \& Entrepreneurship, 26(2), pp.109-124.

Orser, B.J., Riding, A.L. \& Manley, K., 2006. Women entrepreneurs and financial capital. Entrepreneurship Theory and Practice, 30(5), pp.643-665.

Parker, S., C., 2002. DO BANKS RATION CREDIT TO NEW ENTERPRISES? AND SHOULD GOVERNMENT INTERVENE? Scottish Journal of Political Economics, 49(2), pp.162-194.

Peltoniemi, J. \& Vieru, M., 2013. Personal guarantees, loan pricing, and lending structure in Finnish small business loans. Journal of Small Business Management, 51(2), pp.235-255.

Ramsden, M. \& Bennett, R.J., 2005. The benefits of external support to SMEs: "Hard" versus "soft" outcomes and satisfaction levels H. Matlay, ed. Journal of Small Business and Enterprise Development, 12(2), pp.227-243.

Robson, P.J.A. \& Bennett, R.J., 2000. SME Growth: The Relationship with Business Advice and External Collaboration. Small Business Economics, 15(3), pp.193208.

Robson, P.J.A., Jack, S.L. \& Freel, M.S., 2008. Gender and the use of business advice: evidence from firms in the Scottish service sector. Environment and Planning $C$ : Government and Policy, 26(2), pp.292-314.

Rostamkalaei, A. \& Freel, M., 2016. The cost of growth: small firms and the pricing of bank loans. Small Business Economics, 46(2), pp.255-272.

Scott, J.M. \& Irwin, D., 2009. Discouraged advisees? The influence of gender, ethnicity, and education in the use of advice and finance by UK SMEs. Environment and Planning C: Government and Policy, 27(2), pp.230-245.

Shaw, P.J.A.R. \& Bennett, R.J., 1999. Central Government Support to SMEs Compared to Business Link, Business Connect and Business Shop and the Prospects for the Small Business Service. Regional Studies, 33(8), pp.779-787.

Stiglitz, J. \& Weiss, A., 1981. Credit rationing in markets with imperfect information. The American economic review, 71(3), pp.393-410.

Stinchcombe, A. \& March, J., 1965. Social structure and organizations. Advances in strategic management, 17, pp.229-259.

Storey, D.J., 2003. Entrepreneurship, Small and Medium Sized Enterprises and Public Policies. In Z. J. Acs \& D. B. Audretsch, eds. Handbook of Entrepreneurship Research. Great Britain: Kluwer Academic Publishers, pp. 473-511. 
Treichel, M. \& Scott, J., 2006. Women-Owned businesses and access to bank credit: Evidence from three surveys since 1987. Venture Capital: An International Journal of Entrepreneurial Finance, 8(1), pp.51-67.

Trevelyan, R., 2008. Optimism, overconfidence and entrepreneurial activity. Management Decision, 46(7), pp.986-1001.

Vos, E. et al., 2007. The happy story of small business financing. Journal of Banking \& Finance, 31(9), pp.2648-2672.

Westhead, P. \& Storey, D.J., 1997. Financial constraints on the growth of high technology small firms in the United Kingdom. Applied Financial Economics, 7(2), pp.197-201.

Wren, C. \& Storey, D.J., 2002. Evaluating the effect of soft business support upon small firm performance. Oxford Economic Papers, 54(2), pp.334-365.

Xiang, D., Worthington, A.C. \& Higgs, H., 2015. Discouraged finance seekers: An analysis of Australian small and medium-sized enterprises. International Small Business Journal, 33(7), pp.689-707.

Yaniv, I., 2004. Receiving other people's advice: Influence and benefit. Organizational Behavior and Human Decision Processes, 93(1), pp.1-13. 